\title{
"A escola tá mais... escolar": a implantação do tempo integral em uma escola de Ensino Fundamental na perspectiva discente
}

\section{"The school is more... schooled": the implementation of full-time system in an Elementary School in the students' perspective}

\author{
Dília Maria Andrade Glória ${ }^{1}$
}

\begin{abstract}
RESUMO
Este artigo tem por objetivos analisar, a partir da ótica discente, como tem sido a implantação do tempo integral em uma escola pública de Ensino Fundamental e contribuir para a discussão e a avaliação das políticas educacionais no país acerca desta temática. Para tanto, realizou-se um estudo qualitativo em que se fez uso de entrevistas individuais semiestruturadas e grupos focais junto a alunos, observação do cotidiano escolar e análise documental. Verificou-se que o alunado queixa-se de forma recorrente do cansaço advindo com a forma pela qual os tempos e os espaços escolares têm sido utilizados e ressignificados com a adoção do tempo integral. O grupo pesquisado tende a reconhecer a importância do capital escolar, mas enfatiza especialmente o aspecto socioafetivo presente na escolarização. A perspectiva discente é que a escola está ainda "mais escolar": conteudista, desenvolvendo o mesmo tipo de atividades, pouco atraentes, em espaços convencionais e/ou inadequados, e tornando o processo de ensino-aprendizagem insuficientemente producente. Assim, se faz necessária uma adequação pedagógica do tempo-espaço escolar, garantindo-se novas e diversificadas oportunidades de aprendizagem, com maior respeito às demandas dos educandos.
\end{abstract}

Palavras-chave: tempo integral; alunos; Ensino Fundamental; escola pública.

DOI: $10.1590 / 0104-4060.43960$

1 Universidade Federal de Minas Gerais. Centro Pedagógico. Observatório Sociológico Família-Escola. Belo Horizonte, Minas Gerais, Brasil. Av. Antônio Carlos, nº 6627. Campus Pampulha. CEP: 31270-901.E-mail: diliamag@uol.com.br 


\begin{abstract}
This article aims to analyze, in the students' perspective, how the deployment of the full-time system at a public Elementary School has happened, and to contribute to the discussion and evaluation of educational policies in the country on this issue. To this end, there was a qualitative study in which we used semi-structured individual interviews and focal groups with students, observing the school routine and document analysis. It was found that students recurrently complain of fatigue arising from the way time and school spaces have been used and reinterpreted with the adoption of a fulltime system. The researched group tends to recognize the importance of the educational capital, but emphasizes the socio-affective aspect specifically present in the school. The students' perspective is that the school is still "more educational": full of content, developing the same type of activities, unattractive, in conventional and/or inadequate spaces, and making the insufficiently productive teaching-learning process. Thus, it is necessary to try an educational adequacy of school time-space, ensuring new and diverse learning opportunities, with greater respect to the demands of the students.
\end{abstract}

Keywords: full-time school; students; Elementary School; public school.

\title{
Introdução
}

Nas últimas décadas, a escola brasileira tem vivenciado propostas que almejam a qualidade da educação escolar para todos enquanto cerne das políticas públicas educacionais (CURY, 2005), como a reorganização dos tempos e dos espaços escolares, em especial pelo regime de ciclos; o princípio de não retenção escolar; as classes de aceleração; a ampliação de oito para nove anos no Ensino Fundamental, etc. Nessa perspectiva, cada vez mais, a implantação de escolas de tempo integral se configura como pauta constante na agenda da política educacional e no meio acadêmico em geral. (RESENDE, 2009; GLÓRIA, 2013).

No entanto, cabe indagar se a notável expansão de escolas de tempo integral, como investimento do poder público no sistema educacional brasileiro, corresponde a uma demanda social por esse tipo de escola e por quê. Importa pesquisar que concepções e/ou representações estão sendo veiculadas sobre a adoção do tempo integral. (MAURÍCIO, 2009). E mesmo que haja consenso sobre sua necessidade e viabilidade como política pública, a implantação de escolas de tempo integral apresenta-se ainda como um tema pouco contemplado sob a perspectiva daqueles que são o objeto primeiro de seus propósitos democráticos e inclusivos, ou seja, os alunos e as suas famílias. (GLÓRIA, 2014). Este 
artigo objetiva, pois, identificar, na percepção dos estudantes, quais alterações ocorreram com a implantação do tempo integral na escola pesquisada, haja vista um melhor desempenho discente; bem como contribuir para a discussão e a avaliação das políticas públicas no Brasil acerca desta temática.

\section{Metodologia}

A metodologia utilizada na pesquisa foi qualitativa e fez-se uso de entrevistas individuais semiestruturadas e grupos focais junto a alunos, bem como observação do cotidiano escolar e análise documental.

Como campo de pesquisa optou-se pelo Centro Pedagógico (CP), escola pública de Ensino Fundamental da Universidade Federal de Minas Gerais (UFMG), onde o tempo integral foi implantado em 2011. Considerada referência, em especial pelas condições de existência melhores do que em outros estabelecimentos públicos de ensino (maior autonomia; corpo docente qualificado; equipamentos de boa qualidade, etc.), o CP apresenta uma realidade semelhante à de outras escolas públicas, uma vez que os alunos ingressam por sorteio e pertencem majoritariamente às camadas menos favorecidas, em termos socioeconômicos e culturais. Assim, estudar se a implantação do tempo integral no $\mathrm{CP}$ tem contribuído para a melhoria da qualidade educacional e de que maneira isso tem acontecido mostra-se relevante de modo a apontar caminhos possíveis para a rede pública de ensino e contribuir para o debate nacional em curso.

O procedimento inicial foi o de contatar alguns profissionais da educação para se definir um número pequeno de sujeitos, haja vista a natureza qualitativa do estudo, que requer aprofundamento na obtenção e na análise dos dados.

Para se avaliar se há diferença em função do pertencimento social, foram considerados seis alunos oriundos de camadas populares e seis de camadas médias. Para essa categorização, consideraram-se dois critérios: o nível de renda familiar e a escolaridade materna - uma vez que, em geral, as mães são quem acompanham mais de perto a escolarização dos filhos.

No ano de 2012, foram entrevistados individualmente doze alunos: seis cursando o $4^{\circ}$ ano; e seis, o $8^{\circ}$ ano escolar. Decorridos oito meses, os mesmos sujeitos foram ouvidos via técnica do Grupo Focal ${ }^{2}$ (NETO; MOREIRA; SUCENA, 2002), de maneira a identificar, mediante o diálogo e o debate entre eles,

2 Os alunos Artur ( $5^{\circ}$ ano) e Pedro ( $9^{\circ}$ ano) não participaram do grupo focal por terem faltado à aula no dia. 
possíveis alterações em sua compreensão do tema, seja em função do tempo transcorrido, seja pela interlocução com seus pares. Para tanto, foram agrupados de acordo com o ano escolar de pertencimento.

A opção por entrevistar alunos de duas faixas etárias deveu-se, sobretudo, ao entendimento de que a adesão ao tempo integral seria maior em relação às crianças dos anos iniciais, uma vez que são esses alunos cujas famílias demandam maior necessidade de cuidados em termos sociais e morais. Além disso, "[...] a tutela, típica da ação escolar, é algo que incomoda particularmente ao jovem de classe popular, que, em geral, adquire mais cedo sua independência de locomoção e de autocuidados". (CAVALIERE, 2009, p. 57).

Para se preservar, na medida do possível, a fidedignidade dos dados coletados, as entrevistas foram gravadas, mediante autorização, e posteriormente transcritas. Todos os sujeitos citados tiveram seus nomes alterados para garantia do anonimato.

O exame do material discursivo obtido com a realização das entrevistas e dos grupos focais foi efetuado por meio da Análise de Conteúdo (BARDIN, 2000), ou seja, por categorias presentes nas narrativas dos entrevistados, apreendidas por meio de elementos significativos e dimensões mais relevantes de acordo com os objetivos definidos.

\section{O que dizem os alunos entrevistados sobre a escola de tempo integral}

Os alunos participantes da pesquisa souberam que o CP passaria a ser escola de tempo integral no final do ano anterior à sua implantação, em 2010, quando ocorreu uma reunião com as famílias para a entrega de fichas avaliativas - nessa ocasião, os responsáveis presentes receberam um fôlder comunicando a mudança - e/ou através de comentários de colegas e/ou de conhecidos. A princípio, o tempo integral era das $8 \mathrm{~h}$ às $16 \mathrm{~h} 30$, sendo dois módulos de aula na parte da manhã e dois à tarde. ( $c f$. FIGURA 1 - ESTRUTURA DO TEMPO INTEGRAL EM 2011).

As primeiras impressões dos alunos sobre a implantação do tempo integral não foram boas, em especial por se sentirem muito cansados pelo extenso tempo passado na escola, bem como pelo tipo de atividades desenvolvidas. Não obstante terem apreciado a redução do horário a partir de $2012-7 \mathrm{~h} 30$ às $15 \mathrm{~h} 10$, com três módulos de aula (1h30 cada) pela manhã, com intervalos de 20 e depois de 10 minutos entre as aulas geminadas; e um módulo de aulas após o almoço (que passou a ser das $12 \mathrm{~h} 30$ às $13 \mathrm{~h} 40$ ) -, a queixa por causa do cansaço e do 


\section{FIGURA 1 - ESTRUTURA DO TEMPO INTEGRAL EM 2011}

\section{Centro Pedagógico Uma escola de tempo integral}

As aulas no Centro Pedagógico serão distribuídas ao longo do dia, sem diferenciações de turno regular e extra-turno. Sendo assim, terá uma ampliação de tempo escolar para todos os seus alunos. Além disso, a intenção é consolidar o Centro Pedagógico como um espaço significativo de formação de professores e demais profissionais que tenham a escola como campo de atuação e trabalho.

O Tempo Integral tem os seguintes objetivos: (I) propiciar uma maior permanência da criança e do adolescente na escola; (II) democratizar o acesso às práticas esportivas; (III) ampliar o acesso às manifestações culturais e de lazer e (IV) contribuir na formação de alunos dos cursos de graduação da UFMG, possibilitando a eles uma vivência e um exercício da docência em uma escola de tempo integral.

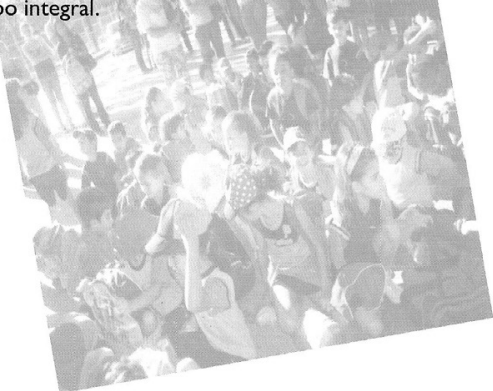

\section{ESTRUTURA DO TEMPO} INTEGRAL

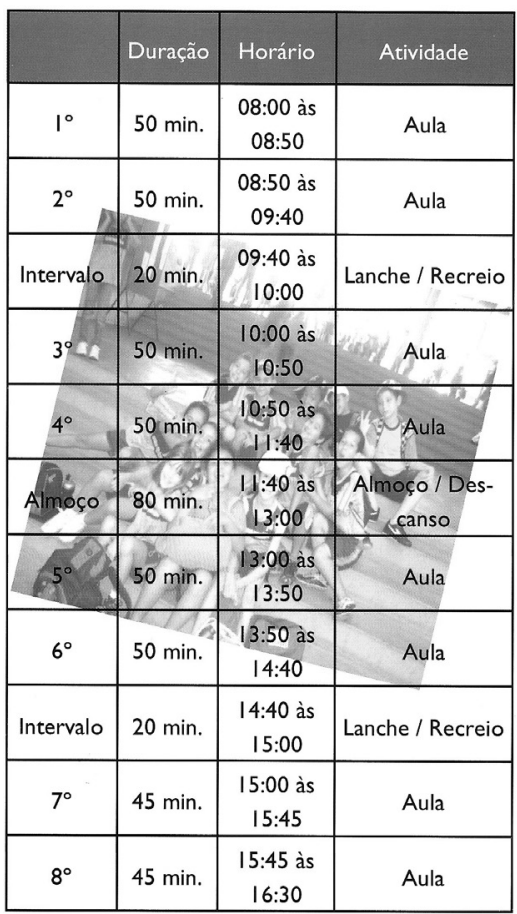

FONTE: Fôlder “CENTRO PEDAGÓGICO UFMG - Uma Escola de Tempo Integral 2011”.

desânimo dos alunos por terem que acordar muito cedo persiste e é recorrente em suas narrativas, independente da faixa etária e do grupo social.

Eu achei horrivel [riso]! Eu tava acostumado à tarde e ia começar a acordar cedo. Ai eu tinha muita preguiça de levantar... E também eu achei o horário das aulas muito longo. Assim, tinha a sensação que demorava demais pra acabar. Muito cansativo! (Mateus, 9 anos, $4^{\circ}$ ano, família de camada média, grupo focal). 
GLÓRIA, D. M. A. "A escola tá mais... escolar": a implantação do tempo integral em uma escola...

Bruna: A gente chega em casa, ainda tem que estudar mais porque às vezes tem prova, Para Casa, e não sobra tempo pra outras coisas, tipo atividade extracurricular ou tempo pra descansar. Eu achei muito cansativo! Daniel: Até hoje é cansativo!

Gustavo: Até no Facebook a gente fica cansado, não tem nem graça mexer lá, porque cê tá com sono...

Daniel: Igual eu, quando chego em casa, faço isso aqui ó [representa que dormiu]!

Jeferson: Tá ficando muito cansativo!

Entrevistadora: No início?

Jeferson: Até hoje! Não sobra tempo procê fazer mais nada!

Bruna: Só que esse ano tá menos cansativo porque reduziu...

Daniel: Reduziu o horário.

( $9^{\circ}$ ano, grupo focal).

Quando indagado sobre o que conhece acerca da proposta de tempo integral no CP, o grupo discente revela desconhecimento e comete equívocos ao relacionar qualquer mudança ocorrida à implantação. A ideia é a de que as alterações na vida escolar, de um modo geral, devem-se ao tempo integral, como (1) a participação no Projeto Um Computador por Aluno (UCA), mediante o qual a escola recebeu computadores portáteis para uso discente; (2) a retirada da cantina que comercializava alimentos; (3) a percepção de que o número de aulas das disciplinas foi "dobrado" porque elas passaram a ser geminadas; (4) a adoção de conceitos ao invés de notas no processo de avaliação, etc.

Cabe esclarecer que a disciplina denominada Grupo de Trabalho Diferenciado (GTD) passou de duas para cinco vezes por semana e suas aulas são quase todas ministradas por graduandos bolsistas da UFMG, sob orientação e/ ou coordenação de docentes do CP. Nessas aulas, os alunos são redistribuídos em grupos no próprio ciclo, independente do ano escolar. O chamado GTD CP ocorre duas vezes na semana, de acordo com a identificação pelos professores do que são tidas como demandas discentes - dificuldade na aprendizagem e/ou ampliação curricular. Quanto ao GTD CEU - assim denominado porque parte das aulas ocorre no Clube Esportivo Universitário (CEU) da UFMG -, acontece três vezes na semana e abrange atividades esportivas diversas, mediante $\mathrm{o}$ Programa Segundo Tempo, por convênio firmado com o Ministério do Esporte.

Daniel: Deixa eu falar?! Deixa eu falar que eu vou falar bonito agora! Eles aumentaram o tempo, tava dando tipo um "migué" [gíria: significa que estavam enganando], falando que três vezes na semana iam dar uma aula de esporte que você escolhesse, mas, na verdade, pra mim, eles es- 
tavam querendo mesmo só aumentar o tempo da aula nosso. Porque eles fizeram isso mesmo só pra gente não falar que fica o dia inteiro trancado dentro da sala. E sendo que terça e quinta-feira, cê quase morre, fica o dia inteiro sentado com a bunda na carteira...

Gustavo: E nem põem cadeira macia!

Daniel: E nem pode falar nada! Se pede pra ir no banheiro, eles falam com você "vai rápido", não dá nem procê dar uma...

Bruna: Mas eu acho que se eles falam isso é pro seu bem!

Daniel: Tá bom, tá bom [irônico]! Aí não dá nem pra gente dar uma relaxada e tal [risos]...

Gustavo: O que eu fiquei sabendo sobre o tempo integral, implantado aqui no Centro Pedagógico, foi que os alunos aqui estavam com problema em rendimento escolar. Minha mãe me explicou que os alunos estavam com o rendimento baixo, tava muito fraco. [...] Ai eles colocaram, eles pegaram e implantaram isso meio que à força, pra ver. Ai aumentaram [o tempo escolar]. Só que ajudaram alguns sim, alguns melhoraram, mas outros pioraram por causa do cansaço, né?!

Lucas: Porque tem gente que consegue, agora tem gente... Só cansaço! [...] Eles obrigaram a gente...

Daniel: Foi tenso!

( $9^{\circ}$ ano, grupo focal).

A princípio, além da compreensão discente de a implantação do tempo integral ter sido forçada, a percepção do grupo parece se restringir à ampliação da jornada escolar, sobretudo através do GTD, e à ideia de que esse aumento do tempo se traduziria em melhoria do desempenho escolar.

No que concerne aos ciclos frequentados pelos alunos entrevistados $\left(2^{\circ}\right.$ ciclo $-4^{\circ}$ ao $6^{\circ}$ ano - e $3^{\circ}$ ciclo $-7^{\circ}$ ao $9^{\circ}$ ano), é importante atentar que das 40 horas/aula distribuídas semanalmente, dez são destinadas ao GTD. Assim, não obstante o grande benefício para a formação de professores, essa disciplina apresenta-se como ponto frágil da proposta, uma vez que se encontra vinculada a acordos políticos e/ou a programa governamental para subsistir. De outro lado, no Projeto acerca da implantação do tempo integral (CENTRO PEDAGÓGICO, 2010), não há ementas das disciplinas - apenas a carga horária semanal -, nem princípios para agrupamento dos alunos nos GTDs.

Ainda em relação a mudanças curriculares, nos ciclos em questão, passou-se a ter uma hora/aula a mais nas disciplinas de Ciências, Geografia, História, Matemática, Português; de Arte no $2^{\circ}$ ciclo e de TEPE (Tópicos Especiais em Práticas Educativas) no $3^{\circ}$ ciclo. As turmas desses dois ciclos passaram a ter duas horas/aula de Língua Estrangeira por semana: $4^{\circ}$ e $5^{\circ}$ anos, Espanhol; $6^{\circ}$ e $7^{\circ}$ anos, Francês; $8^{\circ}$ e $9^{\circ}$ anos, Inglês. Contudo, Arte deixou de ser ofertada para 
GLÓRIA, D. M. A. "A escola tá mais... escolar": a implantação do tempo integral em uma escola...

os alunos do $3^{\circ}$ ciclo, à medida que nessa disciplina as turmas são divididas em duas e não há professores em número suficiente que possam arcar com o modelo em curso. Esse fato causou - e ainda causa - grande polêmica. Outro ponto debatido é o fato de que a disciplina TEPE seja lecionada apenas no $3^{\circ}$ ciclo. Assim, seja pelas circunstâncias de sua rápida implantação e/ou por arranjos internos, a organização curricular do tempo integral no CP parece carecer de maiores fundamentação pedagógica e sustentação política.

Ao ser indagado especificamente sobre algumas mudanças na estruturação e/ou reorganização escolar em função da implantação do tempo integral, o grupo discente não identificou alterações na avaliação e na relação estabelecida com os professores ${ }^{3}$.

Dentre os aspectos observados pelos alunos como objeto de mudança, há relato de um número maior de pessoas responsáveis por prestar apoio ao trabalho pedagógico, em especial pela presença de um monitor em sala de aula para colaborar no processo de ensino-aprendizagem.

Quanto aos espaços escolares, os alunos sentem que ficaram muito prejudicados, sobretudo por não terem lugar para lazer como antes e nem mesmo para descansar.

Senti que agora tá ficando menos espaços... Pra brincar eles estão tirando muitas coisas... A gente tem que ficar discutindo com os meninos pela quadra lá embaixo, os meninos do $3^{\circ}$ Ciclo. Fala que lá é deles... O pátio, também passa professor toda hora, por isso também não dá pra jogar muito. Pra descansar, tem só os banquinhos, mesmo assim não é muito bom porque os meninos também brincam lá de cartinha [jogos de baralho], de bafão, de beyblade [espécie de pião japonês em versão tecnológica]... (Fábio, 9 anos, $4^{\circ}$ ano, família de camada popular).

Bruna: Não tem espaço pra descanso, que eu saiba. Ia pedir muito que a gente tinha uma sala? A gente pode ficar na escada conversando... É o máximo! Mas isso não é um descanso! [...] No início do ano passado, eles reuniram os alunos e falaram algumas coisas que a gente queria e tal, tipo aumentar espaço de descanso...

Daniel: Nada foi feito!

3 No grupo focal, embora alguns alunos do $3^{\circ}$ ciclo tenham mencionado maior "proximidade" em função do tempo de convivência ter sido ampliado, suas falas foram permeadas por um tom jocoso como "Eu tô quase casando com a Estela [professora], praticamente.", "Até no Facebook, eles [professores] tão lá já! Já são da família já!", "Eu já até enjoei dos professores! De tanto que a gente vê eles!", etc. 
Bruna: Espaço de descanso, espaço de lazer, esse negócio... Não fizeram absolutamente nada do que a gente falou! Aumentaram sala de aula... Tiraram Brinquedoteca e colocaram sala de aula. Tiraram sala de música e colocaram sala de aula. [...] Destruíram Laboratório de Informática pra fazer sala de aula!

Gustavo: E o Laboratório de Ciências também! Eram três laboratórios, né?!

( $9^{\circ}$ ano, grupo focal).

De fato, para possibilitar a implantação do tempo integral, vários espaços foram "transformados" em salas de aula: Brinquedoteca, Sala de Música, Laboratórios de Informática e de Ciências, etc. Tais mudanças, além do sério impacto na vivência dos alunos diante de aspectos importantes, como socialização, descanso, envolvimento, etc., resultam ainda em prejuízos pedagógicos em diversas áreas do conhecimento. A questão é que, ao se falar sobre escola integral, importa considerar as variáveis tempo, com referência à ampliação da jornada escolar, de como esse tempo tem sido pensado e articulado, inclusive quanto à diversidade curricular; e espaço, no que diz respeito aos territórios em que cada escola está situada, bem como ocupado em função de sua proposta pedagógica. Nessa ótica, constata-se que a reapropriação pedagógica do tempo-espaço educativo (GONÇALVES, 2006) no CP não tem propiciado a vivência de novas oportunidades de aprendizagem como almejado.

Em relação à alimentação, a maior parte dos alunos diz gostar, embora reclame de aspectos como a pouca variedade quanto ao que é servido ou a não apreciação de alguns alimentos. Há que se admitir, contudo, a dificuldade de qualquer instituição, que sirva refeições, em agradar a todos. A complicação maior parece ser que, rotineiramente, alguns alunos não fazem as refeições como esperado ou mesmo não almoçam. Ressaltem-se ainda diferenças importantes em relação aos grupos: os alunos dos anos iniciais são alvo de uma preocupação maior por parte da família; e os menos favorecidos socioeconomicamente são os que mais apreciam as alterações ocorridas, ao passo que os demais costumam trazer seu próprio lanche. Assim, por mais que a escola busque se incumbir de aspectos até então da alçada familiar, algumas questões, como alimentação e tempo/espaço para lazer e descanso, apresentam-se ainda como desafios importantes.

Acerca da relação família-escola, os alunos compreendem que a família, representada pela mãe ${ }^{4}$, está mais presente e atuante no meio escolar, principal-

4 Qualquer que seja a situação familiar, quase sempre é sobre a mãe que repousa a responsabilidade da escolarização dos filhos, razão pela qual se tem falado no meio acadêmico de uma "matricentralidade" (CADOLLE, 2000) nas famílias contemporâneas. 
GLÓRIA, D. M. A. "A escola tá mais... escolar": a implantação do tempo integral em uma escola...

mente pelos filhos permanecerem um tempo maior na instituição. Segundo os relatos, a preocupação familiar refere-se a questões diversas, como aprendizado, alimentação, segurança, etc.

Ana Beatriz: Antes, ela [mãe], tipo assim, ela não ficava muito preocupada, agora ela fica: "Foi bem na escola? Almoçou direito?".

Fábio: A minha familia não tá se preocupando tanto porque sabe que essa escola é boa, ai ela sabe que eu tô seguro, aí ela não fica perguntando tanto assim!

Mateus: A minha é a mesma coisa...

Ana Beatriz: Ela [mãe] sempre envolveu nas reuniões, sempre ia, nunca deixou de faltar; só que o que eu acho que atrapalhou, que eu acho que atrapalhou, foi esse negócio aí do almoço, sabe? Da gente não almoçar em casa, que ela fica perguntando, fica meio insegura.

( $5^{\circ}$ ano, grupo focal).

Bruna: Acho que a minha mãe tá mais presente aqui, né? É, ela tá mais presente nas reuniões, sabe, preocupando mais comigo, porque antes não era muito assim não...

Daniel: A minha mãe tá vindo mais na escola que antigamente. Minha mãe fica bolada, ela acha assim, que se cê passa mais tempo na escola, cê aprende mais. Então ela fica esperando um boletim, assim, excepcional [enfático]. E não vem excepcional. Ai ferra, né?

Jeferson: Mudou porque a minha família agora ficou mais ligada, né, porque eu passo mais tempo aqui do que em casa! A minha família ficou mais ligada aqui, procurando saber o que que aconteceu, o que que eu faço, o que que eu não faço...

( $9^{\circ}$ ano, grupo focal).

A suposição de que as famílias dos alunos menores seriam mais favoráveis à implantação do tempo integral não se verificou, uma vez que as mães parecem ficar apreensivas por não conseguirem acompanhar o cotidiano escolar do filho. Além disso, diverso do esperado, a percepção de um maior acompanhamento familiar com a implantação do tempo integral mostrou-se mais evidente nos relatos dos alunos dos anos finais. Uma vez que a literatura sociológica indica maior envolvimento das famílias cujos filhos são menores, a ótica discente aqui apresentada traz uma nova perspectiva para os estudos sobre a relação família-escola, em se tratando da ampliação da jornada escolar, o que parece merecer mais pesquisas direcionadas para essa temática. 
Quanto à relação do aluno com a própria família, quase todo grupo discente afirmou que a adoção do tempo integral impactou fortemente nos laços antes existentes.

Fábio: Eu acho que não tô mais envolvendo tanto com minha família porque eu não converso mais tanto quanto conversava antes com a minha mãe e com meu pai, não brinco tanto quanto eu brincava com a minha irmã... Mateus: Eu não tô vendo tanto a minha família. Por exemplo, quando eu acordo, meu pai trabalha cedo, minha mãe fica tipo caminhando... Aí, quando eu chego em casa, ela também não tá lá, nem meu pai. Aí só fica eu e a empregada.

Ana Beatriz: Em relação da família comigo, eu acho que tá bom, que tem tempo, temos momentos... Porque o meu pai trabalha em casa mesmo, ele fez o escritório dele em casa mesmo. Minha mãe é do lar, igual à da Marina, aí dá pra ver, né?

Marcela: Eu quase não vejo nem meu pai e nem a minha mãe! Porque eu vou pra escola de manhã cedo, ai meu pai não tá em casa porque meu pai trabalha o dia inteiro. Ai quando eu chego em casa, eu vejo a minha mãe só um pouco, o meu pai não tá lá, e minha mãe vai pra escola [estudar] e eu fico sozinha em casa... Eu quase não vejo eles [pais]!

( $5^{\circ}$ ano, grupo focal).

O alunado lamenta não dispor mais do mesmo tempo passado com a família como antes, sendo que discentes do $3^{\circ}$ Ciclo se queixam que mal veem a mãe no decorrer da semana. Nos relatos, alguns dizem não ter momentos de lazer junto à família mesmo nos finais de semana, em função de deveres escolares. Com efeito, há narrativas contundentes sobre a dificuldade e/ou a impossibilidade para realizar os deveres de casa. Embora a proposta de implantação do tempo integral alerte que os deveres escolares sejam "alvo de reflexão e redimensionamento" (CENTRO PEDAGÓGICO, 2010, p. 12), averigua-se que essa ideia ainda não se concretizou.

Gustavo: Oh, a Estela [professora], ela já até acostumou já! Em vez dela perguntar quem não fez o Para Casa, ela pergunta quem fez o Para Casa. Bruna: Eu também não tenho muito tempo pra fazer Para Casa não! Mas não é por isso que eu vou deixar de fazer não! Eu chego da escola, tomo um banho, faço o Para Casa, vou pro curso, volto do curso, vou fazer Para Casa. Fico até dez horas acordada fazendo Para Casa.

Gustavo: Eu também sou desse jeito, muito dedicado [diz irônico]! 
GLÓRIA, D. M. A. “A escola tá mais... escolar”: a implantação do tempo integral em uma escola...

Lucas: Eu também faço quando dá. Mas agora tem menos tempo pra fazer, cê chega em casa cansado, não tem como a gente fazer. Mas a maioria das vezes...

Daniel: Eu falo mesmo “Eu não quero fazer Para Casa!” porque eu chego cansado!

Bruna: Eu faço, porque se eu não fizer, eu vou mal.

Jeferson: Cê estuda o dia inteiro, aí o dia que cê fica em casa, cê vai estudar?

Entrevistadora: Então o Jeferson está concordando com o Daniel. É isso? Daniel: Lógico, véio!

Lucas: Eu não, eu concordo com ela [Bruna].

Gustavo: Eu continuo fazendo [Para Casa]. Quando tem muito Para Casa, cê vai até dez, onze... É bom que cê vê televisão.

Daniel: Vai nessa que eu vou ficar até dez horas...

( $9^{\circ}$ ano, grupo focal).

Essa problemática nos traz elementos importantes a serem repensados, como o acompanhamento das atividades escolares que se espera das famílias e a marcação de deveres escolares em uma escola de tempo integral. Segundo Resende (2012), mesmo que haja consenso sobre a importância dos deveres de casa e de seu acompanhamento familiar, a escola precisa estar atenta às concepções e às práticas curriculares vinculadas a essa questão. Para ela, convém ainda considerar a desigualdade de condições para a realização do dever de casa e o seu acompanhamento no âmbito familiar, sobretudo pela diversidade de estratégias dos diferentes grupos sociais, ressaltando-se as dificuldades das famílias de camadas populares.

Aliás, no que concerne a discrepâncias relacionadas à origem socioeconômica e cultural, distintamente do grupo menos favorecido, os alunos de camadas médias entendem que o tempo integral não os favorece em seu desempenho escolar, uma vez que já não conseguem realizar como antes as atividades extracurriculares.

Antes eu tinha, à tarde, quase todo dia da semana, inglês; matemática particular, português; fazia aula de tênis no clube; rugby-é futebol americano -, eu fazia também todo dia da semana, 3 horas da tarde; inglês, até melhorei muito meu inglês... Mas aí, por causa do tempo integral, eu fui obrigado a sair do inglês, fui obrigado a sair da aula de guitarra, que eu também fazia... Só aula particular de matemática e de português que eu continuei. (Lucas, 13 anos, $8^{\circ}$ ano, família de camada média). 
Assim, aulas de língua estrangeira, atividades esportivas e/ou artísticas concebidas como "um 'apoio escolar' menos direto", mas eficazes por contribuir para o bom desempenho escolar (DURU-BELLAT; VAN ZANTEN, 1999, p. 178) - não têm sido devidamente consideradas pelo $\mathrm{CP}$, como apresentado na proposta inicial, segundo os alunos entrevistados.

Ainda no terreno das desigualdades sociais, a perspectiva de o tempo integral tratar-se de uma medida assistencialista foi apresentada pelos alunos do $3^{\circ}$ ciclo quando da realização do grupo focal:

Jeferson: Fiquei sabendo ai que eles também colocaram tempo integral porque os alunos tavam saindo da escola e tavam indo pras ruas, tava mexendo com coisas erradas assim... Ai eles queriam aumentar o tempo ai pra eles não ter tempo de pensar coisas erradas. Praticar. Daniel: Não entendi até hoje que coisa errada que a gente faz! Gustavo: Uso de drogas! Bebidas alcoólicas! [Sussurra de modo irônico.] Daniel: Mas repara procê vê: quando o governo vai falar nisso, nessas coisas, fala que é por causa disso, pra tirar as crianças da rua...

Lucas: Mas eu não conheço nenhum drogado na escola!

Daniel: Não, eu conheço um! [Risos] Eu conheço um! Mas, assim, eles usaram essa "desculpa", entre aspas assim, pra falar pra gente ficar mais tempo na escola. Falam que tão "tirando as crianças da rua" [muda o tom de voz para mostrar tratar-se de citação], que não sei o quê!

( $9^{\circ}$ ano, grupo focal).

Nessa visão assistencialista, o sentido atribuído à escola, de ser um espaço de socialização e refúgio da violência do mundo externo (GLÓRIA, 2003), mostra ter sido intensificado com a escolarização em tempo integral. Por sua vez, tal percepção parece constituir-se nas interações junto a discursos que circulam em diversos âmbitos - família, escola, vizinhança, mídia, etc. De todo modo, a indicação de que as escolas de tempo integral apresentam-se como demanda de grupos populares, atreladas a políticas sociais, em geral de caráter assistencialista (GUARÁ, 2009), é aqui corroborada. Tais considerações são emitidas em especial pelos alunos pertencentes às camadas populares, cujo entendimento é o de que mais tempo na escola equivale a mais aprendizado. Embora prefira somente um turno de estudo - em especial pelo cansaço e pela falta de tempo para o lazer e estar com a família e os amigos -, o grupo discente tende a acreditar que a escola de tempo integral contribui para o aprendizado dos alunos e, por conseguinte, para o sucesso escolar. 
GLÓRIA, D. M. A. "A escola tá mais... escolar": a implantação do tempo integral em uma escola...

Mateus: Assim, aprende mais, eu acho que aprende mais, tem mais matéria, tem mais tempo pra estudar..

Fábio: É, eu também acho a mesma coisa... Que por causa do tempo maior a gente vai ter mais aulas e ter mais conteúdo, e aprender mais, tendo um sucesso maior.

Marina: Eu acho que é bom e a gente pode aprender mais nas aulas.

Marcela: Vai ajudar a gente a ter sucesso na vida sim. É... A gente vai passar mais tempo na escola aprendendo.

Ana Beatriz: Só que tá deixando a gente muito cansada. Entende?

Marina: Cansada e confunde a cabeça...

Ana Beatriz: Às vezes fica lá toda hora falando assim, às vezes o tempo não passa rápido, ai fica falando toda hora assim, explicando a matéria... Fábio: Às vezes não! Sempre!

( $5^{\circ}$ ano, grupo focal).

Daniel: Eu acho que quanto mais tempo cê passa na escola, melhor, mais cê aprende. Mas cansa também!

Bruna: Depende de cada aluno [fala pausadamente e com ênfase].

Gustavo: Depende da matéria.

Daniel: Quanto mais tempo cê passa fazendo uma coisa, melhor cê vai fazer ela. Cê não acha não?!

Bruna: Isso é relativo.

Gustavo: Quanto mais tempo de treinamento, melhor cê vai conseguir.

Daniel: É. Quanto mais tempo cê joga bola, melhor cê é.

Bruna: Isso é relativo, gente! Depende de cada aluno! Eu acho que depende da dedicação de cada um. Tem gente que fica aqui na escola para fazer gracinha. Não vou citar nome porque isso é antiético.

Daniel: Isso é óbvio! Depende de cada um, se ele fez mesmo por merecer.. Bruna: A gente fica esse tempo todo na escola, só que tem gente que vem pra cá e não desfruta desse tempo. Agora, vamos supor que a pessoa estuda só de manhã, mas ela chega em casa, ela cria o hábito e estuda. Ela estuda pelo menos meia hora, uma hora... Ela sabe usar o tempo dela. Mas tem gente que vem pra cá pra falar que veio, só pra isso.

Daniel: É melhor que ocê aprende mais. Se eu for falar por mim, pra mim adianta. Porque eu sei mais coisa do que antes, entendeu?

Jeferson: Só d'ocê vim na escola, já aprende já.

Daniel: É, mais ou menos! Cê aprende assistindo aula!

Gustavo: Porque quanto mais tempo cêfica aqui, tirando esse negócio de cansaço, disso e daquilo, quanto mais tempo, melhor cê fica...

Lucas: $\hat{E}$, cê aprende mais, só que não consegue absorver o que cê aprende. Mais ou menos isso. Tem muita matéria!

( $9^{\circ}$ ano, grupo focal). 
A compreensão que a maior parte dos estudantes apresenta é que estar mais tempo na escola permite a assimilação do conhecimento, como se não fosse preciso se mobilizar para aprender. No entanto, em sua relação com a escola, o aluno sempre terá que se confrontar com alguma espécie de renúncia, seja ela provisória ou não, o que implica outras formas de interação consigo, com os outros e com o mundo - renúncia esta que será tanto maior quanto maior for o envolvimento com o saber escolar. (CHARLOT, 2000). Observa-se ainda a impregnação do discurso meritocrático na percepção discente, que credita o fracasso ou o sucesso escolar às características "naturais" do sujeito - inteligência, motivação, habilidades psíquicas -, quando há vários fatores intervenientes, como meio familiar, social, clima escolar, efeito professor, etc.

Por fim, há que se ressaltar que a leitura discente que perpassa praticamente todas as narrativas é que a implantação do tempo integral no $\mathrm{CP}$ parece ter resultado em "perdas" de ordem socioafetiva e cognitiva no processo de escolarização.

Gustavo: Sabe o que é? No começo da aula fica todo mundo de boa e tal. Passou o horário de almoço... [Daniel: Nuuu!] Fica todo mundo nervoso, doido pra dá três e dez pra rachar fora daqui. [...]

Bruna: Eu acho bom porque a escola conseguiu desenvolver bem esse Projeto [implantar o tempo integral]. A estrutura. Apesar de ter destruido alguns espaços, que eu fiquei muito triste com isso, mas a escola conseguiu atingir o objetivo.

Gustavo: Eu não considero a nossa escola com estrutura pra dá esse tempo todo de aula. Por exemplo, até as escolas de bairro mesmo, têm estrutura, têm salas pra usar, têm o alimento bacana, têm professores pra fazer isso... Agora, cê chega aqui no Centro Pedagógico, nem sala... Eles que construíram as salas aqui, assim, super rapidão, destruíram um monte de espaço! Não temos espaço pra descansar. Ai eu não sei como que eles não destruíram a Biblioteca ainda.

Daniel: A escola tá mais assim, né, mais...

Jeferson: Escolar.

( $9^{\circ}$ ano, grupo focal).

De um modo geral, a avaliação discente é que a proposta de tempo integral do CP caracteriza-se pelo "escolacentrismo", uma vez que, face às demandas sociais postas à escola, responde-se com mais escola e "com a mesma escola". (LOPES, 2012, p. 29). 


\section{Considerações finais}

As narrativas discentes acerca da adoção do tempo integral no Centro Pedagógico indicam aspectos importantes a serem (re)pensados, inclusive no que concerne ao cerne da proposta em si. Há que se considerar a importância de se escutar e envolver a comunidade escolar, especialmente os alunos e suas famílias. Isso, não somente para efeito de conhecimento, mas de contribuições, e em diversas esferas, como: reorganização curricular, revisão do trabalho educacional família-escola - deveres de casa, atividades extracurriculares, acompanhamentos familiar e escolar do processo de ensino-aprendizagem -, número necessário de profissionais da educação a se responsabilizar por aspectos como alimentação e monitoramento de atividades extraclasse, etc.

Importante destacar que a realização de grupos focais mostrou-se um efetivo instrumento metodológico no caso desta pesquisa. Como presumido, por vezes alguns alunos mudaram suas falas, aparentemente influenciados pelas ideias de seus pares, ou mesmo porque, depois de transcorridos alguns meses, não possuíam mais a mesma percepção sobre a questão abordada. Outro aspecto interessante foi o fato de que alguns alunos ficaram mais à vontade para expor seu ponto de vista e outros se mostraram mais reticentes em relação à entrevista concedida individualmente. A interação em grupo contribuiu, portanto, para propiciar uma observação mais apurada da perspectiva discente sobre o tempo integral e para confirmar e/ou ampliar a compreensão aqui apresentada acerca de suas percepções.

No que tange a possíveis diferenças em razão da faixa etária e do grupo social de pertencimento, observou-se relatos inesperados. $\mathrm{O}$ grupo de alunos dos anos finais revelou uma aquiescência maior, tanto de sua parte como de suas famílias, ao tempo integral; ao passo que os estudantes mais novos disseram da apreensão e da insegurança familiar pela demanda de cuidados maiores no que diz respeito à alimentação e à segurança, por exemplo. No que concerne a discrepâncias relativas à origem socioeconômica e cultural, nota-se uma insatisfação maior do grupo pertencente às camadas médias, uma vez que os alunos dizem da dificuldade e/ou da impossibilidade de continuar com as atividades extracurriculares desenvolvidas antes do tempo integral. Segundo eles, a escola não tem conseguido propiciar devidamente aulas de língua estrangeira, prática de esportes, oficinas de arte, etc., como apresentado quando da implantação do tempo integral.

Para além dessas diferenças, os alunos pesquisados concebem o tempo integral como medida oriunda de uma demanda da sociedade, fundada em uma concepção mais assistencialista do que formativa. Além disso, não obstante acreditarem que tal proposta possa favorecer o aprendizado e o sucesso escolar 
- ainda que com fundamentos pouco sólidos de sua parte -, são unânimes ao afirmar que preferem um turno de estudo ao turno integral. Pelo que se percebe, essa perspectiva do alunado decorre da forma pela qual o tempo/espaço escolar tem sido utilizado e ressignificado com a proposta de escola de tempo integral em curso. Os sentimentos que permeiam a maior parte das falas são de cansaço e de perda, pois gostariam de mais tempo/espaço para brincar e/ou descansar na escola (e fora dela) e de mais momentos junto da família e dos amigos. Em suma, a dificuldade maior ressaltada pelos alunos é que a escola de tempo integral apresenta-se "mais escolar" do que nunca, ou seja, conteudista, com o mesmo tipo de atividades, pouco atraentes, em espaços convencionais e/ou inadequados, o que os deixa muito cansados e pouco producentes.

Em contraponto às narrativas maternas - que, mesmo valorizando a função social da escola, concebem o desenvolvimento de competências cognitivas como papel central -, os alunos tendem a reconhecer a importância do capital escolar em sua vida, mas evidenciam o quão crucial são os aspectos socioafetivos no processo de escolarização. A perspectiva discente é a de que se faz necessária uma adequação pedagógica do tempo-espaço escolar, garantindo-se novas e diversificadas oportunidades de aprendizagem, com respeito às condições dos educandos. Os alunos alertam, pois, para o fato de que se as políticas públicas ambicionam "qualificar" as escolas por meio da implantação do tempo integral, se requer um enfrentamento sério aos desafios postos, em especial na articulação de tempos e de espaços condizentes à complexa e multifacetada realidade que se apresenta.

\section{REFERÊNCIAS}

BARDIN, L. Análise de conteúdo. Lisboa, Portugal: Edições 70, 2000.

CADOLLE, S. Etre parent, être beau-parent: la recomposition de la famille. Paris: Odile Jacob, 2000.

CAVALIERE, A. M. Escolas de tempo integral versus alunos em tempo integral. Em Aberto, Brasília, v. 22, n. 80, p. 51-63, abr. 2009.

CENTRO PEDAGÓGICO (UFMG). CP - uma Escola de Tempo Integral. Belo Horizonte, 2010. Projeto.

CHARLOT, B. Da relação com o saber: elementos para uma teoria. Porto Alegre: ARTMED Editora, 2000.

CURY, C. R. J. Políticas inclusivas e compensatórias na Educação Básica. Cadernos de Pesquisa, São Paulo, v. 35, n. 124, p. 11-32, jan./abr. 2005. 
GLÓRIA, D. M. A. "A escola tá mais... escolar": a implantação do tempo integral em uma escola...

DURU-BELLAT, M.; VAN ZANTEN, A. Sociologie de l'école. Paris: Armand Colin, 1999. Chapitre 9: Les pratiques éducatives des familles. p. 167-187.

GLÓRIA, D. M. A. A “escola dos que passam sem saber”: a prática da não-retenção escolar na narrativa de alunos e familiares. Revista Brasileira de Educação, Campinas, n. 22, p. 61-76, jan./fev./mar./abr. 2003.

GLÓRIA, D. M. A. Escolas de tempo integral como política pública de inclusão. Presença Pedagógica, Belo Horizonte, v. 19, n. 113, set./out. 2013.

GLÓRIA, D. M. A. Escola de tempo integral na visão de algumas famílias: entre o ideal e o real. Revista de Educação PUC-Campinas, Campinas, v. 19, n. 3, 2014. Disponível em: $<$ http://periodicos.puc-campinas.edu.br/seer/index.php/reveducacao/article/view/2851>. Acesso em: 22 set. 2015.

GONÇALVES, A. S. Reflexões sobre educação integral e escola de tempo integral. Cadernos Cenpec - Educação Integral, São Paulo, n. 2, 2006. Disponível em: <www.crmariocovas.sp.gov.br/pdf/es_tempointegral/reflexoes_ed_integral.pdf>.Acesso em: 04 out. 2010.

GUARÁ, I. M. F. R. Educação e desenvolvimento integral: articulando saberes na escola e além da escola. Em Aberto, Brasília, v. 22, n. 80, p. 65-81, abr. 2009.

LOPES, J. T. Do politeísmo cultural contemporâneo ao trabalho escolar de eliminação da dissonância. In: DAYRELL, J. et al. (Org.). Família, escola e juventude: olhares cruzados Brasil-Portugal. Belo Horizonte: Editora UFMG, 2012. p. 24-37.

MAURÍCIO, L. V. Escritos, representações e pressupostos da escola pública de horário integral. Em Aberto, Brasília, v. 22, n. 80, p. 15-31, abr. 2009.

NETO, O. C.; MOREIRA, M. R.; SUCENA, L. F. M. Grupos Focais e Pesquisa Social Qualitativa: o debate orientado como técnica de investigação. In: ENCONTRO DAASSOCIAÇÃO BRASILEIRA DE ESTUDOS POPULACIONAIS, XIII., 2002, Ouro Preto. Violências, o Estado e a Qualidade de Vida da População Brasileira. ABEP - Associação Brasileira de Estudos Populacionais. Unicamp, 2002, p. 1-26. Disponível em: <http://www.abep.nepo. unicamp.br/docs/anais/pdf/2002/Com_JUV_PO27_Neto_texto.pdf $>$. Acesso em: 19 abr. 2011.

RESENDE, T. de F. Experiências brasileiras de ampliação do tempo de permanência do aluno na escola: concepções, formatos e efeitos. Actas do Encontro "Contextos educativos na Sociedade Contemporânea", v. I - Comunicações. Lisboa: Secção de Sociologia da Educação da Associação Portuguesa de Sociologia, 2009. p. 113-122. Disponível em: <http:/www.aps.pt/cms/imagens/ficheiros/FCH4ac6715cd94cf.pdf>. Acesso em: 04 out. 2010.

RESENDE, T. de F. Dever de casa, espelho de desigualdades educacionais e sociais. Educação em Revista, v. 28, n. 3, p. 159-184, set. 2012. Disponível em: <http://www. scielo.br/pdf/edur/v28n3/a08v28n03.pdf>. Acesso em: 12 nov. 2015.

Texto recebido em 16 de novembro de 2015. Texto aprovado em 20 de janeiro de 2016. 